\title{
Knowledge, attitudes and beliefs about HIV among Young People - A baseline Survey in Navsari and Dang Districts of Gujarat
}

\author{
Mamtarani, Kosambiya J. K, Saxsena Deepak, Patel Bharat, Chaudasma Rajesh, Desai V. K \\ Department of Community Medicine, Government Medical College, Surat
}

\section{ABSTRACT}

Title of the article: Knowledge, attitudes and beliefs about HIV among Young People- A baseline Survey in Navsari and Dang Districts of Gujarat. Objectives: To assess the knowledge and attitudes and beliefs of young people of rural and tribal areas as regards reproductive health, sexuality, STIs and HIV/AIDS Study design: Cross-sectional. Setting: rural and tribal areas of Navsari and Dang Districts of Gujarat Participants: young people of 15-24 years and 25-49 years age group. Methods: Using cluster sampling technique 30 Clusters (15 Navsari and 15 Dang) were surveyed in January and February 2007. Data entry and analysis was done using Epi-info software. Results \& Conclusion: Total of 2144 young people were interviewed. The major sources of information about HIV/AIDS were mass media and friends. Half (50\%) of young people had heard about HIV/AIDS. A majority of young people were aware of all four modes of transmission of it. About three-fourth of the young people ( $75 \%$ ) believed that it can be prevented. The results signify that although some amount of awareness is prevalent in the study area; further efforts are needed to bring awareness about reproductive health, sexuality and HIV/AIDS. The awareness programs need to focus on strategies of prevention especially emphasizing the role of condoms in preventing HIV/AIDS and other STIs. Education programs should focus on the most vulnerable groups the adolescent girls and young women- who are less aware as compared to men about different methods of prevention.

Key words: HIV/AIDS, young people, awareness, attitudes

\section{INTRODUCTION}

Acquired Immuno Deficiency Syndrome (AIDS) though a disease only about 20 years old, now has evolved into a pandemic effecting millions of people worldwide. The prevalence rates are far higher in developing countries where STD treatment is less accessible ${ }^{1}$. More than half of all new HIV infections occur among people under the age of 25 years, and almost 11.8 million youth are living with HIV or AIDS., ${ }^{2,3}$ They have grown up in a world changed by AIDS but many still lack comprehensive and correct knowledge about how to prevent

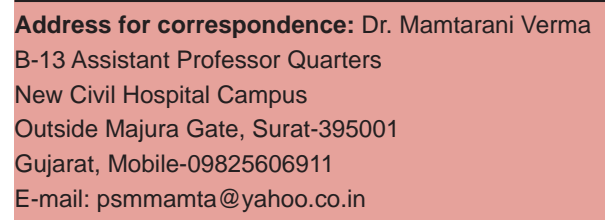

DOI: 10.5530/ijmedph.4.2011.5
HIV infection. This situation persists even though the world has agreed that young people have the human right to education, information and services that could protect them from harm.

The virus spreads in India mainly through the heterosexual route. Sexual behaviours and choices are an intensely private matter and difficult to change. Therefore awareness regarding HIV/AIDS is crucial for HIV/ AIDS prevention and control.

With young men and women bearing the brunt of the disease burden, it is essential that we educate our youth on healthy lifestyles. NACO is working on coming up with a health education package that will focus on healthy lifestyle which will say no to unsafe sexual behaviour, no to tobacco, no to alcohol and no drugs. Above all, treatment is available to delay the death of person suffering from the disease; however there is no cure. Thus it becomes necessary to educate young people to protect themselves from getting infected. 
Earlier most of the studies taken up had concentrated on high-risk group or some single-key population such as school children/adolescents ${ }^{4,5,6}$, prisoners ${ }^{7}$, rural or urban population ${ }^{8}$, women ${ }^{9,10}$ and drivers ${ }^{11}$ etc. As very few studies were taken up to assess the awareness levels in general population, the present study was undertaken to highlight the lacunae in the knowledge with respect to modes of transmission and methods of prevention of HIV/AIDS as well as to explore attitudes towards prevention, treatment and cure of a person with HIV/AIDS.

\section{MATERIALS AND METHODS}

The study was essentially a survey conducted between February and March 2007 in Navsari and Dang districts (Gujarat) by the Department of Community Medicine, Government Medical College, Surat. In the survey of young population in the community two forms: Form 1 and Form 2 were used. Form 1 was used to fill up the household information such as the names, age, marital status, sex and religion of the members of the household including availability of media such as radio, television or/ and newspapers to the households was obtained. Form 2 included questions related to awareness regarding STI and HIV/AIDS. The possible responses for each question were pre-coded and given along with the questions so that the interviewer can code the responses obtained immediately. Form 1 and 2 and the questionnaire were in local language. The questionnaires were developed by GSACS and they were pre-tested and modified as necessary. A two-day training workshop was organized at the department. Clear and detailed question-by-question instructions to fill-up the forms were given. Each team was advised to fill-up at least one Performa in detail and their queries and doubts were clarified.

A team of four field investigators (PARAS-PSM-PSH Project staff, intern of the department consisting of two male and two female was formed. Two such teams went for data collection in one cluster per day. The supervisors helped during data collection especially with regard to random sampling of households. Care was taken to take the verbal consent of the participants by initially explaining the purpose of the study and knowing their willingness to share the information. After the data collection, care was taken to inform the participants if requested by the participants on the topic under study. This was considered to be the moral duty by the investigators. Data was entered in the computer using Epi-Info Version 6.4 (April 2007). Analysis was also done using the same package.

\section{RESULTS AND DISCUSSION}

A sample size of 2144 was distributed as 1027 males and 1117 females. The present study found that majority i.e. $62 \%$ participants belonged to the $25-49$ years age group. Among 15-24 years age group 40.7\% were males and remaining females. Age group, 25-49 years comprised greater part of females $(62.0 \%)$. In a study done by UNAIDS (2002) - 62 percent of infected youth are female $^{12}$. Young women are more vulnerable to the HIV epidemic than men. Of the 11.8 million HIV-infected youth worldwide, over seven million are female ${ }^{12}$. The virus is more easily passed to young women because of their immature vaginal tracts and easily torn tissues; meanwhile, gender inequities in many countries prevent young women from negotiating safer sexual practices including condom use ${ }^{13}$.

Most of the participants were married (71.7\%) and the largest group was married between the ages of 18-21 years. About one-third of the participants were married below the age of 18 years. The common practice of child and adolescent marriage is an increasingly important factor in the HIV/AIDS epidemic. Married adolescents know less about HIV, are less able to negotiate condom use, and are much more likely to use no method of protection from HIV than their unmarried peers ${ }^{14,15}$. Though $20.6 \%$ of the study participants were illiterate, only $33.9 \%$ had studied up to secondary school only. Labor work was the main occupation among all the participants $(27.8 \%)$. About one-fifth of participants were unemployed with more of females.

\section{Exposure to Media}

Near fifty percent of the participants watch television $(52.0 \%)$ and more than one-fifth listen to radio or read newspaper. Almost similar number of males (52.7\%) and females (50.8\%) watch television. Among those who watch television, near fifty percent watch it in the evening and more than one third at night. Most participants mentioned that they watched television for about 1-2 hours or less. Most of the participants (54.2\%) listen radio in the morning. Similarly among those who read newspaper, read it for less than an hour a day. Thus the exposure to media was observed in the form of $\mathrm{TV}$, newspaper and radio.

\section{Awareness regarding HIV/AIDS}

It was observed that $54.9 \%$ of young people ( $56 \%$ males and $53 \%$ females) had ever heard about HIV/AIDS. This figure is of concern because having heard of HIV is only a first step. People must also be aware of how to 
prevent the disease, along with where to go for testing and treatment. As Multi-pronged strategies are used to reach the masses for creating awareness about AIDS. Here, $77.5 \%$ mentioned that they received information from their friends. A higher percentage of men believed this as compared to women. $49.0 \%$ mentioned that television is the main source of information for them. Newspaper was also source of information for almost one fourth of participants. Very few participants received information from health care providers $(7.0 \%)$.

\section{Awareness regarding modes of spread}

In the present study awareness about different modes of transmission of HIV/AIDS was good $85 \%$, concerning blood transfusion (89\%), sexual transmission (86.5\%), unhygienic needles/syringes (85.4\%) and infected pregnant mother to child (85\%).

When asked whether mosquito bite spreads HIV, about one-fourth felt that mosquito bite could transmit HIV. Similarly, when enquired whether HIV transmits by casual contact with infected person, $28.3 \%$ of the study subjects had the misconception that it can transmit the infection. Slightly higher percentage of males believed this. The belief was stronger among younger age group as compared to older age group participants. Less than one-sixth of participants had no idea about it. This is an indication of the fact that in spite of having awareness, the respondents had lack of complete knowledge about the root cause of HIV/AIDS. Around the world, vast majority of youth have little understanding of HIV transmission or how to protect themselves against HIV. Globally, 33 percent of young men and 20 percent of young women aged 15-24 can correctly identify prevention methods of HIV transmission. According to surveys, in no country were more than half of youth fully educated about HIV transmission and prevention ${ }^{2}$.

\section{Perceptlion regarding PLWH among those who had heard of HIVIAIDS}

Near eighty of participants (78\%) believed that infected people should be allowed to stay in the village. More number of females believed it among the participants of both the age-groups. Likewise when asked whether an infected family member would be accepted; 17\% of participants in both the age-groups assumed that infected should not be allowed to stay in the village or not to eat with an infected person (25\%).

Today, people with HIV/AIDS are regularly discriminated and rejected by their own loved ones. The disease is considered to be a punishment for immoral behaviour. Discrimination can become the hardest part of living with the HIV infection, creating a climate that is a private hell for those infected and affected. In many regions, people with HIV have been thrown out of their homes, rejected by families, turned away from jobs, and had their children expelled from schools. It can spread infection through misunderstanding. Some people with HIV infection go for years without telling a soul. Messages on community based care for HIV positive individuals or people living with AIDS may be delivered ${ }^{16,17}$. When asked whether there is clinic to test HIV, more than one-half mentioned that there is no such clinic. More efforts are needed to make the community fully aware of the prevention and cure of HIV/AIDS.

\section{Awareness regarding condoms}

Only $49.4 \%$ of participants had heard of condom. Those who had heard of condom, a great majority of participants $(>80 \%)$ were aware that it could prevent pregnancy. Only $64 \%$ had the knowledge that its use could prevent HIV/ AIDS. About one-third of the participants were not aware that it prevents STI.

Lande $\mathrm{R}$ in his study observed that sexually transmitted infections (STIs) including HIV continue to present major health, social and economic problems in the developing world, leading to considerable morbidity, mortality and stigma ${ }^{18}$. Also a Strong epidemiological association between HIV and STDs is noted in epidemiological studies $^{1,19,20}$.

Educating youth about condoms does not promote the sexual activity. Baldo $\mathrm{M}$ et al in a research clearly indicates that education about condoms does not lead to increased rates of sexual initiation, lower the age of sexual initiation, or increase sexual activity among young people ${ }^{21,22}$. Furthermore, studies show that consistent and correct condom use can greatly reduce the risk of HIV transmission among sexually active youth ${ }^{23,24}$. Young people who are educated about the health benefits of condoms are more likely than other young people to use condoms when they eventually initiate $\operatorname{sex}^{21,22}$. Knowledge of condoms is obviously a necessary, if not sufficient, condition for their acceptance and use.

\section{Summary}

Our study has observed a good level of awareness towards HIV but more sustained efforts are needed to make the public fully aware of the modes of transmission and prevention of HIV/AIDS. General awareness of HIV/AIDS-related issues must be increased in order that people will understand how to protect themselves, reduce their stigma and discrimination towards people 
living with HIV/AIDS because overcoming stigma and discrimination is the key to control the HIV epidemic.

The various measures, which the government has been implementing, are either not enough to create awareness, or they are not reaching the targeted population. There is an immense need from the side of the government in taking measures, which would make the general public aware of the country's AIDS crisis. Because HIV infection is a dynamic process and could change as a function of time, more and more of similar studies targeted at general population are needed at regular intervals to test the results of the preventive measures and the efficacy of the implemented policies.

Education is the only source of all illumination. As there is no cure for HIV/AIDS or no effective vaccine to prevent HIV/AIDS infection till date, health promotion through extensive "Information, Education and Communication" to influence the behaviour of groups and individuals is the key element in efforts to limit spread of HIV and it remains the single most important component of National AIDS Prevention and Control Programme of any country.

\section{ACKNOWLEDGEMENT}

We would like to acknowledge Gujarat State AIDS Control society, Ahmedabad for the technical and financial assistance for conducting this study. We are grateful to all interns, residents and PARAS PSM PSH project staff members who participated in data collection and contributed for this study in the form of suggestions, review and feedback. The authors thank all the participants who had cooperated in this study.

\section{REFERENCES}

1. Adler M, Foster S, Grosskruth H, Richens J, Slavin H, Sexual Health and health care, Sexually Transmitted Infections, Guidelines for Prevention and Treatment, Health and Population Occasional Paper DFID, London; 1998.

2. ZafrullahAllopathic Private Practioners Training Module, STI/HIVIAIDS Prevention Education (SHAPE). APAC-VHS; Chejournalai: 2000

3. Dobson R. AIDS-dramatic surge in ex-soviet union, no respite worldwide, new data show. Bulletin of WHO/International Journal of Public Health 2001;79:78.
4. Sodhi S, Mehta S. A comparative study of girls of two senior secondary schools of Chandigarh. Man India 1997;77:259-66. [PUBMED].

5. Chakraborty J, Purohit A, Shah S, Kalla S, Purohit S. A comparative study of the awareness and attitude of HIV / AIDS among students living in India and migrants to the United States. J Assoc Physicians India 1996;44: 237-9. [PUBMED].

6. Lim VKG, Teo TSH, Teo ACY, Tan KTL. HIV and Youths in SingaporeKnowledge, Attitudes and Willingness to Work with HIV-Infected Persons. Singapore Med J 1999;40:410-6.

7. Nakhaee FH. Prisoners' knowledge of HIVIAIDS and its prevention in Kerman, Islamic Republic of Iran. East Mediterr. Health J 2002;8: 725-31 [PUBMED].

8. Bhatia V, Swami HM, Kaur AP. An intervention study to enhance AIDS awareness among underprivileged population in Chandigarh. Indian J Dermatol Venereol Leprol 2004;70:87-91.

9. Fung Ho Choi and Yuen Loke Alice. HIVIAIDS knowledge and risk behaviour in Hong Kong Chinese pregnant women. Journal of Advanced Nursing 2003;43:238.

10. Shrotri A, Shankar AV, Sutar S, Joshi A, Suryawanshi N, Pisal H, et al Awareness of HIVIAIDS and household environment of pregnant women in Pune, India. Int J STD and AIDS 2003;14:835-39.

11. Abdelmoneim I, Khan MY, DaffallaA, Al-Ghamdi S, Al-Gamal M.Knowledge and attitudes towards AIDS among Saudi and non-Saudi bus drivers. East Mediterr Health J 2002;8:716-24.

12. UNAIDS et al. Young People and HIVIAIDS: Opportunity in Crisis. Geneva: UNAIDS, 2002

13. Joint United Nations Programme on HIV AIDS (UNAIDS). 2006 Report on the Global AIDS Epidemic, Geneva, Switzerland: UNAIDS, 2006.

14. Lary $\mathrm{H}$ et al. Exploring the Association Between HIV and Violence: Young People's Experiences with Infidelity, Violence and Forced Sex in Dar es Salaam, Tanzania. International Family Plajournaling Perspectives 2004; 30:200-6.

15. Clark S, Bruce J, Dude A. Protecting Young Women from HIVIAIDS: The Case Against Child and Adolescent Marriage. International Family Plajournaling Perspectives 2006;Jun;32(2):79-88.

16. Piyavorawong S, Suebsaeng L. Community Based HIVIAIDS Care: successful model from Thailand. AIDS Watch 2000;1-3.

17. Gilks C, Floyd K, Haran D et al. Sexual Health and Health Care. Care and support for People with HIVIAIDS in resource poor setting. Health and population Occasional Paper, DFID, 1998.

18. Lande R. Controlling Sexually Transmitted Diseases. Population Reports Series L, No.9, Baltimore, John Hopkins School of Public Health, Population Information Programme, June 1993).

19. Nayyar A. Questions and answers on reproductive tract infections and sexually transmitted infections. Population Council, UNFPA.

20. Plummer FA, Simonsen JN, Cameron DW et al. Cofactors in male female sexual transmission of HIV Type I.J. of Infections Disease 1991 163:233-9.

21. Baldo $\mathrm{M}$ et al. Does Sex Education Lead to Earlier or Increased Sexual Activity in Youth? Presented at the Ninth International Conference on AIDS, Berlin, 6-10 June, 1993. Geneva: World Health Organization, 1993.

22. United Nations Joint Programme on HIV and AIDS. Impact of HIV and Sexual Health Education on the Sexual Behaviour of Young People. [UNAIDS Best Practice Collection] Geneva: UNAIDS, 1997.

23. CDC. Condoms and Their Use in Preventing HIV Infection and Other STDs. Atlanta, GA: CDC, 1999.

24. de Vincenzi I. A longitudinal study of human immunodeficiency virus transmission by heterosexual partners. New England Journal of Medicine 1994;331:341-346 [PUBMED]. 